1. S. Yu. Yunusov and G. P. Sidyakin, ZhOKh, 22, 1055, 1952.

2. G. P. Sidyakin and S. Yu. Yunusov, DAN UzSSR, no. 4, 39, 1962.

3. G. P. Sidyakin, M. Eskairov, and S. Yu. Yunusov, ZhOKh, 30, 338, 1960.

4. G. P. Sidyakin, et al., ZhoKh, 32, 4091, 1962.

7 May 1967

Institute of the Chemistry of

Plant Substances, AS UzSSR

UDC $547.944 / 945$

\title{
STRUCTURE OF PERFORINE AND HAPLOPHYLLIDINE
}

Z. Sh. Faizutdinova, I. A. Bessonova, and S. Yu. Yunusov

Khimiya Prirodnykh Soedinenii, Vol. 3, No. 5, p. 356, 1967

The isolation of two new alkaloids, perforine [1] and haplophyllidine [2], from the seeds of Haplophyllum perforatum has been reported previously. These bases are similar in structure and give a number of identical derivatives. The results of a study of the chemical transformations and of the UV, IR, mass, and NMR spectra of perforine (I), haplophyllidine (II), and their derivatives enables the following structures to be proposed for them:

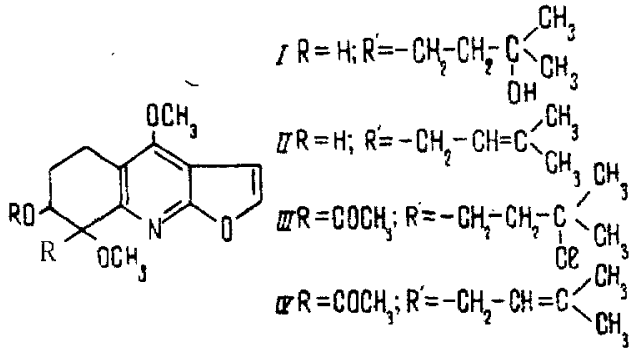

The structural similarity of these alkaloids was shown by a passage from perforine to haplophyllidine by the following route: perforine (I) $\rightarrow$ chloroacetylperforine (III) $\rightarrow$ acetylhaplophyllidine (IV) $\rightarrow$ haplophyllidine (II).

Perforine and haplophyllidine are the first representatives of the series comprising the furano $-5,6,7,8-t e t r a h y d r o-$ quinoline derivatives.

\section{REFERENCES}

1. G. P. Sidyakin, I. A. liessonova, and S. Yu. Yunusov, DAN UzSSR, no. 10, 33, 1959.

2. T. I. Shakirov, G. P. Sidyakin, and S. Yu. Yunusov, DAN LzSSR, no. 8, 47, 1966. 